\title{
The benefits of good teaching extend beyond course achievement
}

\author{
Chad N. Loes ${ }^{1,2}$ and Ernest T. Pascarella ${ }^{3}$ \\ Abstract: This paper synthesizes research from the Wabash National Study on \\ Liberal Arts Education, the National Study on Student Learning, and the \\ Research on Iowa Student Experiences study that estimates the influence of \\ certain effective instructional practices on a range of student outcomes. Student \\ perceptions of two specific teacher behaviors - instructor clarity and instructor \\ organization - are associated with gains in a number of important student \\ outcomes including critical thinking, propensity for lifelong learning, academic \\ motivation, persistence to the second year of college, graduate degree plans, \\ likelihood of obtaining a bachelor's degree, and student use of deep approaches \\ to learning.
}

Keywords: Effective instruction, teaching, cognitive development, critical thinking, persistence.

Although there are hundreds of studies documenting the relationship between effective teacher behaviors and course-level student achievement, there is an emerging body of research suggesting that certain instructional approaches are also linked to a variety of other important outcomes. In this paper, we aim to synthesize what has been learned from three large studies by Pascarella and colleagues that estimate the overall effect of two particularly salient teacher behaviors on a wide-range of personal and cognitive student outcomes theoretically associated with a liberal arts education. We also endeavor to explore what these findings mean for colleges and universities, and explain how they can assist faculty in improving the delivery of instruction, thereby promoting growth in a number of important areas of student development.

There is a vast empirical literature on effective teaching in college. Literally, hundreds of correlational studies, and a limited number of experimental studies, linking student-perceived teaching practices with course-level knowledge acquisition and content mastery have been conducted (see Pascarella \& Terenzini, 1991, 2005; and Perry \& Smart, 2007 for a summary of the evidence). Two of these practices - instructor clarity and instructor organization - have received considerable empirical attention. It is important to note that the terms "instructional clarity" and "instructional organization" refer to student perceptions of these particular behaviors. Although student perceptions are not exact measures of teacher behaviors, they provide useful insight into whether instruction is actually effective. Ideally, the best indicator of good teaching is student learning. Perhaps unsurprisingly, evidence suggests that effective instruction is indeed associated with increased levels of student learning (Benton, Duchon, \& Pallett, 2011). Further, after summarizing studies reviewed by Pascarella and Terenzini (2005), Pascarella, Salisbury, and Blaich (2011) note there are three major conclusions about student perceptions of teacher behaviors and instructional practices: "(a) these perceptions are multidimensional, (b) they are reasonably reliable and stable, and (c) they have moderate

\footnotetext{
${ }^{1}$ Department of History, Politics, and Justice, Mount Mercy University, 1330 Elmhurst Drive NE, Cedar Rapids, Iowa 52402 , cloes@mtmercy.edu

${ }^{2}$ Authorship is in alphabetical order

${ }^{3}$ Department of Educational Policy and Leadership Studies, The University of Iowa, N440 Lindquist Center Iowa City, Iowa 52242, ernest-pascarella@uiowa.edu
} 
positive correlations (e.g., .30 to .50) with various measures of course level learning such as course grade and course final examination" (Pascarella, et al., 2011, p. 5).

As suggested earlier, there is an impressive amount of literature documenting the positive relationship between specific instructional behaviors and course-related knowledge acquisition and student achievement. The literature on this subject is detailed in a number of meta-analyses and syntheses on good teaching (see for example, Abrami, d'Apollonia, \& Rosenfield, 2007; Braskamp \& Ory 1994; Cashin, 1999; Cashin, Downey, \& Sixbury, 1994; d'Apollonia \& Abrami, 1997; Feldman, 1996, 1997; Greenwald, 1997; Marsh, 1987; Marsh \& Dunkin, 1997; Marsh \& Roche, 1997; McKeachie, 1997; Wachtel, 1998). In his synthesis of effective teaching behaviors and student achievement, Feldman (1989) identified 31 specific teaching behaviors for inclusion in his analysis. Many of these instructional approaches (e.g., perceived outcome or impact of instruction, teacher's stimulation of interest in the course and its subject matter, teacher's availability and helpfulness) have relatively substantial, positive correlations with student achievement (.46, .38., and .36, respectively). Among the 31 teaching behaviors identified in the analysis, however, instructor organization and instructor clarity stand out as the strongest correlates of student achievement ( $\mathrm{r}=.56$ and .57 , respectively).

Not surprisingly, the vast majority of this research is correlational. However, the predictive validity of student perceptions of teaching behaviors and instructional practices is not limited exclusively to correlational evidence. At least three of the dimensions of student perceptions of teaching having the strongest positive correlations with course achievement have been vetted with randomized experiments. These include: instructional clarity (clear explanations, effective use of examples), instructional organization (use of course objectives, effective use of class time), and teacher expressiveness (eye contact, speaking emphatically) (Hines, Cruickshank, \& Kennedy, 1985; Schonwetter, Menec, \& Perry, 1995; Wood \& Murray, 1999).

Despite the large body of literature linking clear and organized instruction with student achievement, it was unclear whether these effective instructional practices influenced broader outcomes associated with college attendance. As such, nearly two decades ago, researchers affiliated with the 1992-95 federally-funded National Study of Student Learning (NSSL) hypothesized that, by improving content acquisition, overall exposure to instructional clarity and instructional organization/preparation during college might also enhance the development of more general cognitive skills that are tied less directly to specific course content (Pascarella, Edison, Nora, Hagedorn, \& Braxton, 1996). They reasoned that, by facilitating the effective acquisition of factual knowledge, concepts, and important definitions, overall exposure to clear and organized instruction during college might permit greater emphasis on more general and higher-order cognitive processes and experiences (Feldman, 1994; Pascarella et al., 1996). They based their reasoning on Rabinowitz and Glaser's (1985) argument that sound content knowledge is a necessary foundation on which higher-order and more sophisticated intellectual development is built. Consequently, they developed two 5-item scales termed instructional clarity and instructional organization that appropriated specific items appearing in vetted research on these constructs. The constituent items and internal consistency reliabilities for both scales are shown in Table 1. Because the two scales are substantially correlated (teachers who are clear, tend also to be organized) some studies have also combined them into a single 10-item scale termed instructional clarity/organization. 
Loes, C.N. \& Pascarella, E.T.

Table 1

Constituent Items for the Instructional Clarity and Organization Scales ${ }^{a, b}$

Instructional Organization A five-item scale $(\alpha=0.87)$ that asks the respondents the
following:
1. The presentation of the material is well-organized.
2. Teachers are well-prepared for class.
3. Class time is used effectively.
4. Course goals and requirements are clearly
5. Teachers have good command of what they are
teaching.

Instructional Clarity

A five-item scale $(\alpha=0.86)$ that assesses the extent to which respondents have observed the following teaching behaviors:

1. Teachers give clear explanations.

2. Teachers make good use of examples and illustrations to explain difficult points.

3. Teachers effectively review and summarize the material.

4. Teachers interpret abstract ideas and theories clearly.

5. Teachers give assignments that help in learning the course material.

a Scale stem: "Below are statements about teacher skill/clarity as well as preparation and organization in teaching. For the most part, taking into consideration all of the teachers with whom you've interacted at [institution name], how often have you experienced each?" Response options: 5= "very often"; 4= "often"; 3= "sometimes"; 2= "rarely"; 1= "never." The scale was standardized across items for the entire sample.

b The alpha, internal consistency reliability of the combined "instructional clarity and organization scale" is .89.

A series of analyses of the 1992-95 (NSSL) longitudinal database that controlled for extensive confounding influences, including a pretest, found that the more students reported that the overall instruction they received in college was high on the instructional organization scale, the larger their gains on a standardized, objective measure of critical thinking (Edison, Doyle, \& Pascarella, 1998; Pascarella et al., 1996). Similarly, a more recent analysis of the 1992-95 NSSL data combined the two 5-item scales into the 10-item composite instructional clarity/organization scale. Net of extensive confounding influences, the resultant composite scale had a significant, positive impact on gains in reading comprehension over three years of college (Bray, Pascarella, \& Pierson, 2004). Though only an initial step, such early findings clearly suggested that overall 
exposure to clear and organized instruction during college had positive implications for the development of general cognitive capabilities that were not tied to a specific course. Building on the initial work of the National Study of Student Learning (NSSL), the Wabash National Study of Liberal Arts Education and Experiences (WNS) sought to further our understanding of how overall exposure to clear and organized instruction during college might facilitate student developmental gains in areas beyond individual course achievement. Funded by the Center of Inquiry in the Liberal Arts at Wabash College, the WNS is a large longitudinal multi-institution investigation of the impacts of liberal arts colleges and liberal arts experiences on the cognitive and personal outcomes typically associated with a liberal arts education. Over 40 institutions of all types have participated in the WNS since its inception. However, the findings we report in this article were based largely on the 2006-2010 cohort of 19 institutions (11 liberal arts colleges, 3 regional institutions, 3 major research universities, and 2 community colleges). The 19 institutions in the 2006-2010 cohort were located in 11 different states from 4 general regions of the United States: Northeast, Southeast, Midwest, and Pacific Coast. The participating institutions had a wide range of academic selectivity, from some of the most selective institutions in the country to some that we essentially open admissions. There was also substantial variability in undergraduate enrollment, from institutions with entering classes between 3,000 and 6,000, to institutions with entering classes between 250 and 500 .

Random samples of incoming students were selected from each institution and were assessed at three different points in time: upon entrance to college in the fall of 2006, after the first year of college in the spring of 2007 and at the end of four years of college in spring 2010. At entrance to college in fall 2006 they completed a series of instruments that measured dimensions of cognitive and personal development, such as standardized measures of critical thinking, academic motivation, and the like, as well as providing extensive information on family background and high school experiences. At the end of the first year of college (spring 2007) they again completed the same standardized measures of cognitive and personal development and responded to a set questionnaire instruments that assessed their first year experience of postsecondary education. The questionnaire instruments included level of engagement, as measured by the National Survey of Student Engagement (NSSE), as well as perceptions of overall exposure to clear and organized instruction, as measured by instruments developed specifically for the WNS. At the end of the fourth year of postsecondary education (spring, 2010) the students in the 17 four-year colleges once again completed the standardized instruments measuring cognitive and personal development, as well as the same extensive series of questionnaire items measuring their college experience and overall perceptions of the instruction they received.

Responses to the instructional clarity and organization scale(s) in spring 2007 and spring 2010 presented students with the following stem: "Below are statements about teacher skill/clarity as well as preparation and organization in teaching. For the most part, taking into consideration all of the teachers with whom you've interacted with at [institution name], how often have you experienced each?" They were then presented with the 10 items shown above in Table 1, and four response options from "very often" to "never". All assessments at each institution were directed and administered by ACT located in Iowa City, IA. The results of the analyses we report are based on samples of approximately 3,100 students at all 19 institutions in spring of 2007, and approximately 2,200 students at the 17 four year colleges in the sample in the spring of 2010 . 
The longitudinal, pretest-posttest design of the WNS enabled us to estimate the effects of overall exposure to clear and organized instruction while controlling for an extensive battery of confounding influences. These typically included such influences as: a pretest measure of the outcome/dependent variable, ACT (or equivalent SAT/COMPASS) score provided by each institution, demographic and family background characteristics, high school experiences, educational aspirations, type of institution attended, work responsibilities during college, cocurricular involvement, type of coursework or academic major, and the like. In addition we typically used statistical procedures to adjust for the nested nature of our data (students at each institution tending to behave similarly), and weighted the samples to adjust for student response bias by race, sex, ACT score, and institution.

In an analysis of the data from the first follow-up (spring 2007) of the Wabash National Study, we attempted to test the robustness of an earlier finding from the 1992-95 National Study of Student learning (Pascarella et al., 1996) indicating that overall exposure to organized instruction during the first year of college facilitated first-year gains on a standardized measure of critical thinking skills. Using the same objective, standardized measure of critical thinking skills (The 32-item, multiple-choice Critical Thinking Test of the Collegiate Assessment of Academic Proficiency) as Pascarella et al. (1996), we introduced a battery of controls for such confounding influences as precollege level of critical thinking, ACT (or equivalent) score, precollege academic motivation, type of institution attended, and the liberal arts emphasis of first year coursework. With these controls in place, the instructional organization scale had a modest, but statistically significant positive link with first-year critical thinking gains for the entire sample (Loes, Salisbury, \& Pascarella, 2014). This essentially replicated the same effect reported nearly 20 years ago by Pascarella et al. with the NSSL data.

Utilizing first-year data from the 2006, 2007, and 2008 cohorts of the WNS, Loes, Saichaie, Padgett, and Pascarella (2012) built upon previous work by Mayhew, Wolniak, and Pascarella (2008) that explored whether exposure to certain effective instructional practices were linked to specific cognitive student outcomes. While accounting for a wide-range of confounding variables, including precollege academic ability, race, sex, and pretest measures of the outcomes, they found that instructional clarity and organization were positively associated with gains in a measure of orientation toward complex cognitive activity termed "Need for Cognition," and a higher proclivity to engage in literary activities, termed "Positive Attitude Toward Literacy." These findings held true for all students in the sample, regardless of individual background characteristics.

The work we have reviewed heretofore focuses on the influence of effective instructional behaviors on a variety of student outcomes during only the first year of college. Less is known about the impact of these same teaching behaviors on outcomes over four years of college, however. Next, we synthesize some of the work from Pascarella and colleagues that explores four-year gains in cognitive development and cognitive orientation.

We conducted several studies to estimate the net impact of overall exposure to clear and organized instruction (the 10-item scale) on gains in critical thinking, orientation toward complex cognitive activity and academic motivation (Gillig, Roksa, \& Pascarella, 2013; Pascarella, Wang, Trolian, \& Blaich, 2013; Wang, Pascarella, Nelson Laird, \& Ribera, in press). In these studies we also introduced statistical controls for a battery of confounding influences that included: a precollege measure of each outcome, ACT (or equivalent) score, high school experiences and family educational background, type of institution attended, major field of study, co-curricular involvement, and work responsibilities. Holding such influences constant, 
we found that overall exposure to clear and organized instruction significantly enhanced fouryear gains on a measure of standardized critical thinking skills (the CAAP Critical Thinking Test), NFC, and a measure of academic motivation.

There were also two other findings of potential significance, however. First, students attending liberal art colleges in the WNS sample tended to report significantly higher exposure to clear and organized instruction than did their counterparts attending regional institutions or national research universities - and this association persisted even when controlling for student precollege abilities and orientations. Indeed, most of the positive influence of liberal arts colleges on student cognitive growth was mediated through their (liberal arts college's) distinctive teaching environment. At the same time, it is important to point out that exposure to clear and organized instruction positively enhanced four-year gains in cognitive measures irrespective of the type of institution attended. Second, net of individual precollege abilities and orientations, students reporting greater overall exposure to clear and organized instruction also reported greater use of "deep approaches to learning," such as "integration," "reflection," and "higherorder learning," as measured by the National Survey of Student Engagement completed by WNS respondents during the spring 2010 assessment. This finding is consistent with theoretical expectations that, by facilitating efficient content knowledge, clear and organized instruction may permit a greater emphasis on higher order cognitive processes and experiences. In fact, student use of deep approaches to learning significantly mediated part, though not all, of the influence of overall exposure to clear and organized instruction on four-year gains in critical thinking skills and need for cognition.

In addition to gains in cognitive development and cognitive orientation, exposure to clear and organized instruction also appears to confer advantages to students in their likelihood of persisting to the second year of college, graduate degree plans, and bachelor's degree attainment. Several scholars have hypothesized that the nature and quality of classroom instruction may not only influence student learning, but could also exert a significant influence on persistence or departure from a particular postsecondary institution (Braxton, Hirschy, \& McClendon, 2004; Tinto, 2006-2007). Some direct evidence for this is reported by Braxton, Bray, and Berger (2000). They reasoned that students who are frequently exposed to clear and organized classroom instruction might be more confident and relaxed about their academic achievement. Consequently, these students might perceive that they have more time "to invest the psychological energy necessary to establish membership in the social communities of their college or university" (Braxton et al., 2000, p. 216). In turn, increased social integration would enhance institutional commitment and intent to persist at the institution. Braxton, Bray, and Berger tested this hypothesis at a single institution using a measure of overall instructional clarity and organization essentially identical with Pascarella, et al. (1996). With important confounding influences statistically controlled, overall exposure to clear and organized instruction significantly enhanced both a measure of student social integration and intent to reenroll for the second year of college.

Of course one might argue that "intent" to re-enroll is not as important as the actual act of re-enrolling. Building on the work of Braxton et al. (2000), we therefore assessed the role played by overall exposure to clear and organized instruction during the first year of college on the actual re-enrollment of students for the second year of college at the same institution. Our assessment was based on two completely independent samples, but with nearly identical study designs. The first was a longitudinal study conducted by The University of Iowa's Center for Research on Undergraduate Education titled "Research on Iowa Student Experiences," which 
assessed student experiences at The University of Iowa (Pascarella, Seifert, \& Whitt, 2008), while the second analyzed data from the first year of the WNS (Pascarella et al., 2011). The findings of the two studies were remarkably consistent. With statistical controls in place for important confounding influences, such as ACT (or equivalent) score, educational aspirations, parental education, institutional type, and first-year co-curricular involvement and cumulative grades, the more students reported being exposed to clear and organized instruction during the first year of postsecondary education, the more likely they were to actually re-enroll at the same institution for the second year of college. Furthermore, in both studies the causal mechanism appeared to be a mediated effect through satisfaction with college. That is, overall exposure to clear and organized instruction significantly enhanced satisfaction with college, which, in turn, was a crucial determinant of re-enrollment for the second year of postsecondary education at the same institution.

We followed up our analysis of the influence of exposure to clear and organized instruction on first year persistence by extending the argument to the impact of clear and organized instruction on graduate degree aspirations. Hanson, Paulsen, and Pascarella (2014) analyzed the 2006-10 WNS data to estimate the net influence of overall exposure to clear and organized instruction on graduate/professional degree plans at the end of four years of college. With statistical controls in place for such confounding influences as precollege degree aspirations, ACT (or equivalent) score, precollege academic motivation and need for cognition, institutional type and selectivity, and academic major field of study, overall exposure to clear and organized instruction had a significant, positive link with fourth-year plans to obtain a graduate/ professional degree.

In our final investigation (Loes, An, \& Pascarella, 2015), we built on the results of the Pascarella et al. (2008), and Pascarella et al. (2011) studies to determine if overall exposure to clear and organized instruction during college also contributes to completion of a bachelor's degree within four years. This is a consideration of some importance, as a recent synthesis by Toutkousian, Shafiq, and Trivette (2013) indicates that the greatest lifetime financial returns to individual investment in postsecondary education accrue to those who complete their bachelor's degree. Given the findings from prior research on the link between good teaching and persistence (Pascarella et al., 2008; Pascarella et al., 2011), we also reasoned that the influence of clear and organized instruction on graduating from college in four years would be mediated by one's satisfaction with college. Our analyses of the WNS 2006-10 data introduced statistical controls for such potential confounding influences as ACT (or equivalent) score, precollege degree aspirations and academic motivation, type of institution attended, major field of study, cumulative college grades, co-curricular involvement, and work responsibilities. With such controls in place, students reporting the highest levels of overall exposure to clear and organized instruction during college were significantly more likely than other students to actually complete their bachelor's degree in spring 2010. Further, similar to the Pascarella et al. (2008) and Pascarella et al. (2011) studies on effective instruction, the relationship between exposure to good teaching and graduation was mediated by satisfaction with college. This suggests that the influence of good teaching on bachelor's degree completion is mediated, or transmitted through, one's satisfaction with the college experience (Loes, An, \& Pascarella, 2015).

We begin our discussion on the implications of clear and organized instruction with a note of caution. The body of evidence we have presented in this set of studies from the Wabash National Study is correlational rather than experimental. While the pretest-posttest, longitudinal design of the WNS is one of the most powerful available for estimating college impacts under

Journal of the Scholarship of Teaching and Learning, Vol. 15, No. 2, April 2015. 
natural, rather than experimental, conditions (in which random assignment is possible), causal inference is, at best, tenuous. Our analytical approach throughout has been to posit a significant association between overall exposure to clear and organized instruction and a number of important cognitive and other outcomes that are not tied to specific course content. We then introduced as many important confounding influences as we could to the prediction model to try to reduce that association to zero. The fact that our posited association tends to persist when we take confounding influences into account is not the same as causality from randomized experiments. Rather, it simply means that, given what we have controlled for, we cannot dismiss the possibility of a causal relationship between overall exposure to clear and organized instruction and the various general cognitive and other outcomes we have considered.

That said, the evidence we uncovered has intriguing aspects. Effective teaching is at the core of the undergraduate experience in American postsecondary education. Clearly we should anticipate that it will enhance specific course learning. What is less apparent, and perhaps less expected, is that overall exposure to effective teaching may have positive consequences for cognitive and other outcomes that are not directly tied to specific coursework. Though they are tentative, we offer the following conclusions.

First, and consistent with theoretical expectations, it would appear that overall exposure to clear and organized instruction during college is significantly linked to student use of deep approaches to learning - such as higher-order learning, reflective learning, and integrative learning. Such deep approaches to learning mediate part, though not all, of the cognitive impact of exposure to clear and organized instruction. By facilitating the efficient acquisition of basic content knowledge, clear and organized instruction may permit students (and instructors) to focus on higher-order cognitive processes and experiences.

Second, we now have replicated evidence to suggest that overall exposure to organized instruction during the first year of postsecondary education may modestly, but significantly enhance first-year gains in critical thinking skills (as measured by a standardized instrument). Third, over four years of postsecondary education overall exposure to clear and organized instruction may significantly enhance four-year gains in critical thinking skills, Need for Cognition, and academic motivation. Interestingly, though perhaps not surprisingly, students attending liberal arts colleges reported significantly higher levels of overall exposure to clear and organized instruction than did their counterparts attending national research universities or regional institutions. Indeed, the unique influence exerted by liberal arts colleges on both fouryear gains in critical thinking and orientation toward cognitive activity was substantially mediated through clear and organized instruction. However, this does not mean that clear and organized instruction only matters at liberal arts colleges. Rather, the unique effects of overall exposure to clear and organized instruction persisted irrespective of the type of institution one attended.

Fourth, the positive benefits of overall exposure to clear and organized instruction may not be limited exclusively to the cognitive outcomes of college. Replicated evidence suggests that overall exposure to clear and organized instruction during the first year of college may contribute to student persistence at a particular institution by enhancing students' satisfaction with the education being received. Similarly, overall exposure to clear and organized classroom instruction also appears to make a unique, positive contribution to fourth-year plans for a graduate or professional degree, and completion of one's bachelor's degree within a four-year period. In this sense, what happens in the classroom may contribute, not only to learning, but also to students' persistence and timely progress toward degree completion. 
While it is understandable that faculty members may be most focused on how their instruction facilitates learning in specific courses, our evidence suggests that overall exposure during college to one important dimension of pedagogy, clear and organized classroom instruction, confers general cognitive and other benefits that transcend specific course achievement. Put another way, how well faculty teach in the classroom has potentially important implications that go beyond a specific course to influence students' general cognitive development, institutional persistence, and timely progress toward a bachelor's degree. It is likely that pedagogical competence is to some extent shaped by individual faculty capabilities and interests.

However, improving faculty members' skills in delivering clear and organized classroom instruction may not be totally circumscribed by innate pedagogical skills or professional propensities. As Weimer and Lenze (1997) have argued, faculty members can actually learn many of the constituent skills required to implement clear and organized classroom instruction. Institutional investment of resources in faculty development programs designed to enhance teaching or instructional effectiveness, as well as implementing instructional training as part of doctoral preparation programs, may not only improve course achievement, but also contribute to students' general cognitive growth and successful educational progress. Further, Loes and Salisbury (2013) point out that faculty can estimate the extent to which they are delivering clear and organized instruction by having students in their classes complete surveys that include the items from the instructional clarity and organization scales - that are the same as those used in this study (see Table 1). Doing this could enable faculty to not only determine their overall level of instructional clarity and organization, but it could also permit them to estimate whether there are any specific dimensions of their instructional clarity or organization that need improvement.

As noted earlier, there exists a vast body of literature documenting the positive relationship between effective instruction, generally, and student achievement. The literature we have synthesized here suggests the effect of two specific teaching behaviors (clarity and organization) extend to other important student outcomes theoretically associated with a liberal arts education, such as critical thinking, propensity for lifelong learning, and the like. We believe these findings can serve as a bridge for other teaching and learning research. Specifically, we believe there is much left to learn about the influence of other effective teacher behaviors (e.g., feedback, enthusiasm [Feldman, 1989]) on the outcomes reviewed here. Future research should not be limited to only the outcomes we have synthesized in this paper, however. Indeed, other researchers should test whether these and other teaching behaviors influence additional student outcomes that are championed by institutions throughout higher education. It seems the findings from those investigations could be tied directly back into classroom practices, thus enhancing the student growth that is desired by all institutions of higher education.

\section{Acknowledgements}

This research was supported by a generous grant from the Center of Inquiry in the Liberal Arts at Wabash College to the Center for Research on Undergraduate Education at The University of Iowa. 


\section{References}

Abrami, P., d'Apollonia, S., \& Rosenfield, S. (2007). The dimensionality of student ratings of instruction: What we know and what we do not. In R. Perry \& J. Smart (Eds.), Effective teaching in higher education: Research and practice (pp. 385-456). The Netherlands: Springer.

Benton, S. L., Duchon, D., \& Pallett, W. H., (2011). Validity of student self-reported ratings of instruction. Assessment \& Evaluation in Higher Education, 38(4), 377-388. doi: 10.1080/02602938.2011.636799

Braxton, J. M., Bray, N. J., \& Berger, J. B. (2000). Faculty teaching skills and their influences on the college student departure process. Journal of College Student Development, 41(2), 215-227.

Braxton, J. M., Hirschy, A. S., \& McClendon, S. A. (2004). Understanding and reducing college student departure. ASHE-ERIC Higher Education Report, 30(3). San Francisco, CA: JosseyBass.

Bray, G. B., Pascarella, E.T., \& Pierson, C.T. (2004). Postsecondary education and some dimensions of literacy development: An exploration of longitudinal evidence. Reading Research Quarterly, 39(3), 306-330. doi.org/10.1598/RRQ.39.3.3

Braskamp, L. A., \& Ory, J. C. (1994). Assessing faculty work. San Francisco, CA: Jossey-Bass.

Cashin, W. E. (1999). Student ratings of teaching: Uses and misuses. Unpublished manuscript, Kansas State University, Manhattan.

Cashin, W. E., Downey, R. G., \& Sixbury, G. R. (1994). Global and specific ratings of teaching effectiveness and their relation to course objectives: Reply to Marsh. Journal of Educational Psychology, 86(4), 649-657. doi: 10.1037/0022-0663.86.4.649.

d'Apollonia, S., \& Abrami, P. C. (1997). Navigating student ratings of instruction. American Psychologist, 52(11), 1198-1208. doi: 10.1037/0003-066X.52.11.1198

Edison, M., Doyle, S., \& Pascarella, E. (1998, November). Dimensions of teaching effectiveness and their impact on student cognitive development. Paper presented at the annual meeting of the Association for the Study of Higher Education, Miami, FL.

Feldman, K. (1994, January). Identifying exemplary teaching: Evidence from course and teacher evaluations. Paper commissioned by the National Center on Postsecondary Teaching, Learning, and Assessment. Stony Brook, NY: State University of New York at Stony Brook.

Feldman, K. A. (1996). Reflections on the study of effective college teaching and student ratings: One continuing quest and two unresolved issues. Unpublished manuscript, State University of New York, Stony Brook. 
Feldman, K. A. (1997). Identifying exemplary teachers and teaching: Evidence from student ratings. In R. Perry \& J. Smart (Eds.), Effective teaching in higher education: Research and practice (pp. 368-395). New York, NY: Agathon.

Feldman, K. A. (1989). The association between student ratings of specific instructional dimensions and student achievement: Refining and extending the synthesis of data from multisection validity studies. Research in Higher Education, 30(6), 583-645. doi:

10.1007/BF00992392

Gillig, B., Roksa, J., \& Pascarella, E.T. (2013, November). Predicting change in academic motivation: Academic and social factors. Paper presented at the annual meeting of the Association for the Study of Higher Education, St. Louis, MO.

Greenwald, A. G. (1997). Validity concerns and usefulness of student ratings of instruction. American Psychologist, 52(11), 1182-1186. doi:10.1037/0003-066X.52.11.1182

Hanson, J., Paulsen, M., \& Pascarella, E. (2013). Understanding graduate school aspirations: The effects of good teaching practices (Doctoral Dissertation, University of Iowa). Retrieved from http://ir.uiowa.edu/etd/2513/

Hines, C., Cruickshank, D., \& Kennedy, J. (1985). Teacher clarity and its relationship to student achievement and satisfaction. American Educational Research Journal, 22(1), 87-99. doi: $10.3102 / 00028312022001087$

Loes, C.N., An, B.P., \& Pascarella, E.T. (2015). Does effective classroom instruction enhance bachelor's degree completion? Some initial evidence. Unpublished manuscript. The University of Iowa, Center for Research on Undergraduate Education.

Loes, C. N., Saichaie, K., Padgett, R. D., \& Pascarella, E. T. (2012). The effects of teacher behaviors on students' inclination to inquire and lifelong learning. International Journal for the Scholarship of Teaching \& Learning, 6(2), 1-20.

Loes, C.N., \& Salisbury, M.H. (2013, November). Does race moderate the cognitive impacts of good teaching? Paper presented at the annual meeting of the Association for the Study of Higher Education, St. Louis, MO.

Loes, C.N., Salisbury, M.H., \& Pascarella, E.T. (2014). Student perceptions of effective instruction and the development of critical thinking: A replication and extension. Higher Education, September 2014. doi: 10.1007/s10734-014-9807-0

Marsh, H. W. (1987). Students' evaluations of university teaching: Research findings, methodological issues, and directions for future research. International Journal of Educational Research, 11(3), 253-388. doi: 10.1016/0883-0355(87)90001-2

Marsh, H., \& Dunkin, M. (1997). Students' evaluations of university teaching: A multi dimensional perspective. In R. Perry \& J. Smart (Eds.), Effective teaching in higher education: 
Research and practice (pp. 241-320). New York, NY: Agathon.

Marsh, H. W., \& Roche, L. A. (1997). Making students' evaluations of teaching effectiveness effective: The critical issues of validity, bias, and utility. American Psychologist, 52(11). doi: 10.1037/0003-066X.52.11.1187

Mayhew, M. J., Wolniak, G. C., \& Pascarella, E. T. (2008). How educational practices affect the development of life-long learning orientations in traditionally-aged undergraduate students. Research in Higher Education, 49(4), 337-356. doi: 10.1007/s11162-007-9081-4

McKeachie, W. J. (1997). Student ratings: The validity of use. American Psychologist, 52(11), 1218-1225. doi: 10.1037/0003-066X.52.11.1218

Pascarella, E. T., Salisbury, M. H., \& Blaich, C. (2011). Exposure to effective instruction and college student persistence: A multi-institutional replication and extension. Journal of College Student Development, 52(1), 4-19. doi: 10.1353/csd.2011.0005

Pascarella, E. T., Seifert, T. A., \& Whitt, E. J. (2008). Effective instruction and college student persistence: Some new evidence. New Directions for Teaching and Learning, 2008(115), 55-70. doi: $10.1002 / \mathrm{tl} .325$

Pascarella, E. T., Wang, J. S., Trolian, T. L., \& Blaich, C. (2013). How the instructional and learning environments of liberal arts colleges enhance cognitive development. Higher Education, 66(5), 569-583. doi: 10.1007/s10734-013-9622-z

Pascarella, E., Edison, M., Nora, A., Hagedorn, L., \& Braxton, J. (1996). Effects of teacher organization/preparation and teacher skill/clarity on general cognitive skills in college. Journal of College Student Development, 37(1), 7-19.

Pascarella, E. T., \& Terenzini, P. T. (1991). How college affects students: Findings and insights from twenty years of research. San Francisco, CA: Jossey-Bass.

Pascarella, E.T, \& Terenzini, P.T. (2005). How college affects students (Vol. 2): A third decade of research. San Francisco, CA: Jossey-Bass.

Perry, R. P., \& Smart, J. C. (2007). The scholarship of teaching and learning in higher education: An evidence-based perspective. The Netherlands: Springer.

Rabinowitz, M., \& Glaser, R. (1985). Cognitive structure and process in highly competent performance. In F. Horowitz and M. O'Brien (Eds.), The gifted and talented: Developmental perspectives, (pp. 85-98). Washington, DC: American Psychological Association. doi: $10.1037 / 10054-003$

Schonwetter, D., Menec, V., \& Perry, R. (April, 1995). An empirical comparison of two effective college teaching behaviors: Expressiveness and organization. Paper presented at the annual meeting of the American Educational Research Association. San Francisco, CA. 
Tinto, V. (2006-2007). Research and practice of student retention: What next? Journal of College Student Retention, 8(1), 1-19. doi: 10.2190/4YNU-4TMB-22DJ-AN4W

Toutkoushian, R., Shafiq, M.N., \& Trivette, M. (2013). Accounting for risk of non-completion in private and social rates of return to higher education. Journal of Education Finance, 39(1), 7395.

Wang, J., Pascarella, E.T., Nelson Laird, T.F., \& Ribera, A.K. (in press). Impacts of clear and organized classroom instruction and deep approaches to learning on four-year growth in critical thinking skills and need for cognition. Studies in Higher Education.

Wachtel, H. K. (1998). Student evaluation of college teaching effectiveness: A brief review. Assessment \& Evaluation in Higher Education, 23(2), 191-212. doi:

10.1080/0260293980230207

Weimer, M., \& Lenze, L. (1997). Instructional interventions: Review of the literature on efforts to improve instruction. In R. Perry \& J. Smart (Eds.), Effective teaching in higher education: Research and practice (pp. 154-168). New York: Agathon Press.

Wood, A., \& Murray, H. (1999, April). Effects of teacher enthusiasm on student attention, motivation, and memory encoding. Paper presented at the annual meeting of the American Educational Research Association, Montreal, Canada. 